Article

\title{
Hydrogen Detection with SAW Polymer/Quantum Dots Sensitive Films
}

\author{
Izabela Constantinoiu and Cristian Viespe *(iD) \\ National Institute for Laser, Plasma and Radiation Physics, Laser Department, Atomistilor \#409, \\ 077125 Bucharest-Magurele, Romania; izabela.constantinoiu@inflpr.ro \\ * Correspondence: cristian.viespe@inflpr.ro
}

Received: 11 September 2019; Accepted: 15 October 2019; Published: 16 October 2019 updates

\begin{abstract}
Regarding the use of hydrogen as a fuel, it is necessary to measure its concentration in air at room temperature. In this paper, sensitive composite films have been developed for surface acoustic wave (SAW) sensors, using quantum dots (QDs) and polymers. $\mathrm{Si} / \mathrm{SiO}_{2} \mathrm{QDs}$ were used due to having a high specific surface area, which considerably improves the sensitivity of the sensors compared to those that only have a polymer. $\mathrm{Si} / \mathrm{SiO}_{2} \mathrm{QDs}$ were obtained by laser ablation and analyzed by X-ray diffraction and transmission electron microscopy (TEM). Two types of polymers were used: polydimethylsiloxane (PDMS) and polymethylmethacrylate (PMMA). Polymer and polymer with QDs compositions were deposited on the sensor substrate by drop casting. A heat treatment was performed on the films at $80{ }^{\circ} \mathrm{C}$ with a thermal dwell of two hours. The sensors obtained were tested at different hydrogen concentrations at room temperature. A limit of detection (LOD) of $452 \mathrm{ppm}$ was obtained by the sensor with $\mathrm{PDMS}$ and $\mathrm{Si} / \mathrm{SiO}_{2} \mathrm{QDs}$, which was heat treated. The results demonstrated the potential of using QDs to improve the sensitivity of the SAW sensors and to achieve a heat treatment that increases its adsorption capacity of the gas molecules.
\end{abstract}

Keywords: gas sensor; composite; surface acoustic wave; quantum dots; polymer; hydrogen sensor; SAW sensor; gas detection

\section{Introduction}

Surface Acoustic Wave (SAW) sensors present a great opportunity in the field of gas detection due to their increased sensitivity, the possibility of wireless operation, small size, fast response, and the ability of integration with different receptor materials [1]. These characteristics allow the use of SAW sensors for both different gases (volatile organic compounds, toxic gases, explosives) as well as for biological analytes, such as for biological analytes, proteins, cancer cells, etc. [1]. They work on the principle of transduction, in which an electrical input signal turns into a mechanical wave, then again turns into an electrical signal [2].

The parameters which by their abnormal values can lead to the disturbance of the waves crossing the sensor and producing a frequency shift of the SAW sensors, can be temperature, pressure, mass loading, and acoustic-electric effect [2]. The mass loading effect is one of the most interesting response mechanisms for this type of sensors. This effect is based on the interaction at the level of the sensitive film with the entity that is required to be detected. This mass accumulation at the film level produces a frequency deviation that can be measured. Ideally, the signal obtained should be as high as possible at the lowest analyte concentration.

Until now, several types of materials have been used to develop sensitive films. These include polymers [3,4] metal oxides [5,6], and composite materials [7-9]. Each of these types of materials can improve the sensibility of the film, but by using composite materials we can obtain both new material properties and improved properties. Thus, in this paper, two types of sensitive films will be 
addressed and compared: polymer sensitive films and composite sensitive films made from polymer and quantum dots (QDs) and also the influence of a heat treatment on the sensitive properties of the films will be studied.

It is known that the main advantage of using nanoparticles in this field is given by their large specific surface, which is inversely proportional to their size [7]. QDs are crystalline nanoparticles with small sizes (1-12 nm) [10]. Considering this aspect, the use of QDs for the synthesis of sensitive films represents a relatively new and interesting direction of research [11,12]. One of the synthesis methods for QDs, which ensures the control of the morphology and high purity, is pulsed laser deposition (PLD) $[13,14]$.

Hydrogen is one of the gases for which there is still a great interest in the development of sensors capable of detecting it at the lowest concentrations [15]. It is one of the most abundant elements in the universe and the first element in the periodic table. It is a colorless, odorless, and insipid gas, in normal conditions. It is used in various domains like ammonia synthesis, fat hydrogenation, as well as rocket and car fuel [16]. If it is used as car fuel then it can reduce pollution, but it needs careful monitoring due to its flammable nature.

As thin films for hydrogen detection, palladium is noted for its ability to dissociate the hydrogen molecule [9]. Also, oxidic films [5], as well as composite films [17-19] are often used in the development of hydrogen sensors. Polymers are noted as having a good sensitivity to room temperature, compared to the oxide materials, which most often require high temperature to obtain the signal. Instead, polymers age faster and offer a shorter lifetime in the sensors, compared to the oxide materials $[20,21]$. Thus, the composites of polymers and oxide materials can be a variant for optimizing the properties of the two types of materials, in the field of sensors [21].

Polymethylmethacrylate (PMMA) polymer has good properties for use in electronic and storage devices and sensors. Also, it is noted to have a good thermal stability under different environmental conditions [19,22]. Polydimethylsiloxane (PDMS) is a polymer used because of its low cost, high thermal expansion coefficient, and good adhesion to silicon. It is also used because of its dielectric properties, even in hydrogen sensors $[9,23,24]$.

\section{Materials and Methods}

The SAW sensor was a 'delay-line' type, based on a quartz substrate (ST cut, $X$ propagation, $10 \mathrm{~mm}$ wide, $38 \mathrm{~mm}$ long, $0.5 \mathrm{~mm}$ thick, and $3158 \mathrm{~m} / \mathrm{s}$ velocity), cut in a parallelogram geometry to reduce the effect of SAW reflections from the edges of the piezoelectric substrate [25], with an oscillating frequency of about $69 \mathrm{MHz}$. The gold IDTs with $\sim 150 \mathrm{~nm}$ thickness, were deposited using standard photolithographic techniques onto $10 \mathrm{~nm}$ thick chromium layers to ensure the adhesion of gold on the quartz. The IDTs have a 'double-comb' configuration, which consisted of 50 electrode pairs with a $2500 \mu \mathrm{m}$ acoustic aperture and a $45.2 \mu \mathrm{m}$ wavelength.

$\mathrm{Si} / \mathrm{SiO}_{2}$ QDs were produced by laser ablation method, using an experimental setup made of a stainless-steel chamber, target system, gas handling, focusing lens, and collector. The experiments were conducted in a flow of argon and helium (1 1/min flow rate, $99.99 \%$ purity). The silicon target was irradiated due to the combined rotation-translation movement of the target and the nanoparticles were collected on Millipore filters (pore size $100 \mathrm{~nm}$ ) after 36000 laser shots. The other experimental details regarding the synthesis of QDs were presented in our previous work [26].

Two types of sensitive films have been made: polymeric and composite films made of polymer and QDs. For obtaining polymer films, commercial polymer solvent solutions were enhanced: 950 PMMA (MicroChem, CAS: 100-66-3) and Polyethyleneimine, low molecular weight, water-free (Aldrich, CAS: 25987-06-8). In the case of PMMA, the solvent was anisole and in the case of PDMS, the solvent was toluene. From these two solutions, compositions for composite films were also enhanced. Thus, the concentration of all the composite solutions was $0.005 \mathrm{~g}$ QDs in $5 \mathrm{~mL}$ polymer solution. These were strongly homogenized using ultrasounds. The obtained solutions were deposited by drop casting on the quartz substrate of the sensor. The volume of one drop was $20 \mu \mathrm{l}$. After deposition, a heat treatment 
at $80{ }^{\circ} \mathrm{C}$ was enhanced, with $2 \mathrm{~h}$ dwell. Thus, eight types of films were analyzed, as presented together with its characteristics in Table 1.

Table 1. The composition of sensitive layers of the sensors studied.

\begin{tabular}{cccc}
\hline Polymer & QDs & Thermal Treatment & Sensor Name \\
\hline \multirow{4}{*}{ PMMA } & Yes & No & PMMA QDs \\
& & Yes & PMMA QDs ${ }^{\circ} \mathrm{C}$ \\
& No & No & PMMA \\
& & Yes & PMMA ${ }^{\circ} \mathrm{C}$ \\
PDMS & Yes & Yo & PDMS QDs \\
& No & No & PDMS QDs ${ }^{\circ} \mathrm{C}$ \\
& & Yes & PDMS \\
\hline
\end{tabular}

The sensors were placed in the test chamber, as in Figure 1 and tested for hydrogen detection at room temperature and in synthetic air, using mass flow controllers. The hydrogen concentration was controlled by varying the flow rate of the gases from two cylinders: one with a hydrogen gas mixture $\left(2 \% \mathrm{H}_{2} / 98 \%\right.$ synthetic air) and another with synthetic air $(100 \%)$. The total rate was kept constant at $0.5 \mathrm{~m}-1 \mathrm{~m}$ for all the measurements. The sensitivity, the limit of detection (LOD), and the reversibility of the sensors were determined. Sensitivity is defined as the change in output signal obtained for a change in mass or concentration of the analyte, and represents the coefficient of the linear approximation of the frequency responses [27]. In Hz, LOD provides the signal-to-noise ratios, which in this case are defined as three times the noise level per sensitivity [2]. The noise level was determined by measuring the resonance frequency for $10 \mathrm{~min}$ as a maximum frequency deviation from the trend line, which was found to be around $80 \mathrm{~Hz}$ for all sensors.

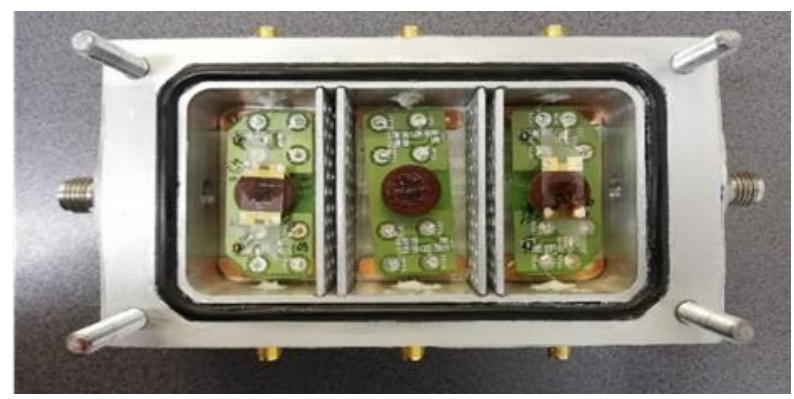

Figure 1. Surface Acoustic Wave (SAW)sensors in the test chamber.

\section{Results and Discussion}

From the X-ray diffraction (XRD) (Figure 2) made on the obtained powder by PLD, the presence of specific peak only for Si was noted (ICDD 00-027-1402) with a lattice constant of $0.54377 \mathrm{~nm}$, almost identical to the standard, which is 0.543088 .

TEM images (Figure 3) indicate the formation of nanoparticles with a spherical shape and dimensions in the $2-13 \mathrm{~nm}$ range. Also, it can be observed that the crystalline core was covered with an amorphous layer of $\mathrm{SiO}_{2}$, which formed as a result of the oxidation process. The photoluminescence effect of these nanoparticles was demonstrated in our previous work [26].

The sensors developed were tested for different hydrogen concentrations, at room temperature. Table 2 shows the sensitivity and LOD. It can be seen that there are three factors that influence the sensitivity and the LOD of the sensors: the polymer used, the presence of QDs, and the heat treatment applied. PDMS is a soft polymer [28], while PMMA is a strong polymer [29]. These characteristics will influence the penetration capacity of the gas molecules in the volume of the polymeric film. After adding QDs, which leads to the growth of the specific surface of the material and to a better 
interaction between it and the gas molecules, the sensitivity of the PDMS QDs sensor is almost double compared to PDMS sensor. Also, it can be observed that the heat treatment applied to the films considerably improves their properties, especially for the films with QDs. This heat treatment has the role of removing organic residues present in the film from the solvents used and promoting the penetration of gas molecules in the volume of the film, due to the formation of cracks on their surface [11].

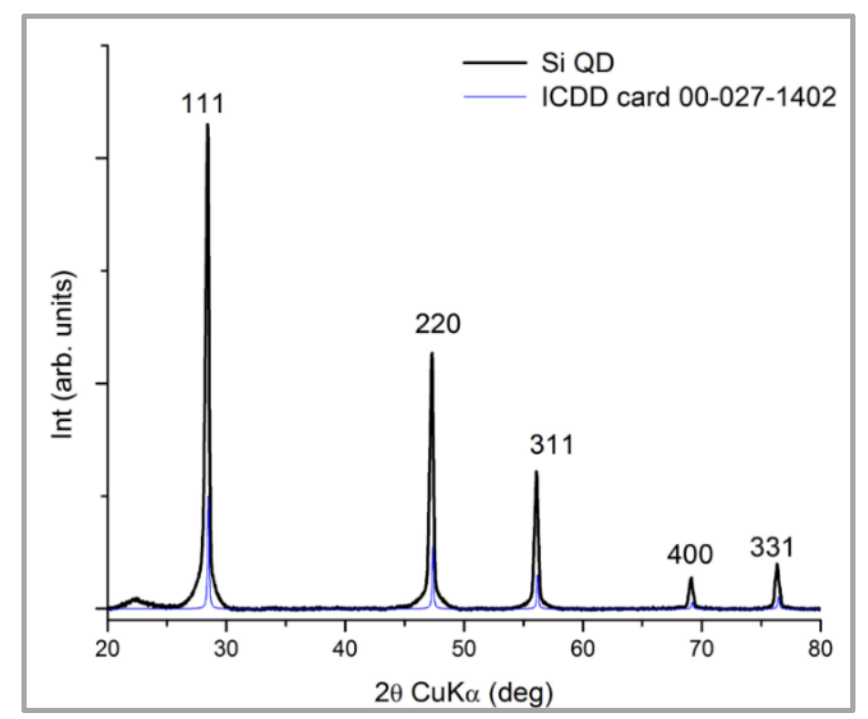

Figure 2. X-ray diffraction (XRD)pattern performed on the synthesized quantum dots (QDs).
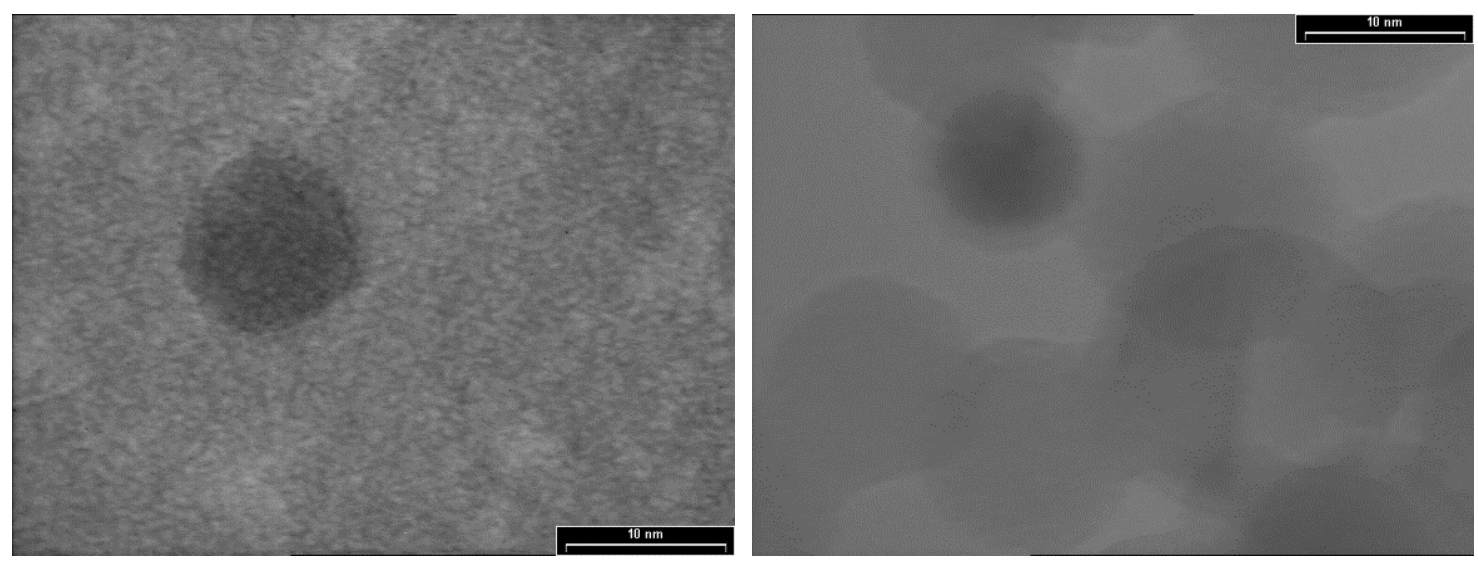

Figure 3. Transmission electron microscopy (TEM)images of $\mathrm{Si} / \mathrm{SiO}_{2}$ QDs.

Table 2. Sensitivity and limit of detection (LOD) for the sensitive films. Legend: $\Delta \mathrm{f}$, frequency change; c, hydrogen concentration.

\begin{tabular}{cccc}
\hline Sensor & Sensitivity $\mathbf{\Delta f} / \mathbf{c}, \mathbf{H z} / \mathbf{p p m}$ & LOD $\mathbf{~ p p m}$ & Noise Level $\mathbf{~ H z}$ \\
\hline PMMA & 0.19 & 1278 & \\
PMMA QDs & 0.34 & 722 & \\
PMMA ${ }^{\circ} \mathrm{C}$ & 0.24 & 1037 & \\
PMMA QDs ${ }^{\circ} \mathrm{C}$ & 0.41 & 589 & \\
PDMS & 0.24 & 1008 & \\
PDMS QDs & 0.43 & 567 & \\
PDMS ${ }^{\circ} \mathrm{C}$ & 0.31 & 797 & \\
PDMS QDs $^{\circ} \mathrm{C}$ & 0.54 & 452 & \\
\hline
\end{tabular}


The average thickness of the deposited films was $2 \mu \mathrm{m}$, measured with a profilometer SURFCOM 180A (Tokyo Seimitsu, Tokyo, Japan).

The addition of QDs in the polymeric sensitive films led to an obvious increase in the sensitivity, observed both in Table 2 and Figure 4. The frequency shift for composite films was about $40 \%$ higher than those with only polymer. The heat treatment also influenced the frequency shift recorded by the sensors, as can be seen in Figure 5. After the heat treatment of the sensors with QDs, an increase of the frequency shift of about 20\% was determined both for PMMA QDs and PDMS QDs. The difference of the frequency shift between the sensors with only polymer, PMMA and PDMS, and the sensors with QDs and heat treatment (PMMA QDs ${ }^{\circ} \mathrm{C}$ and PDMS QDs ${ }^{\circ} \mathrm{C}$ ) was the most appreciable, with increased values of about 53\% for sensors with PMMA and about 55\% for those with PDMS. Of all the sensors made, the best results were obtained for those with PDMS polymer.

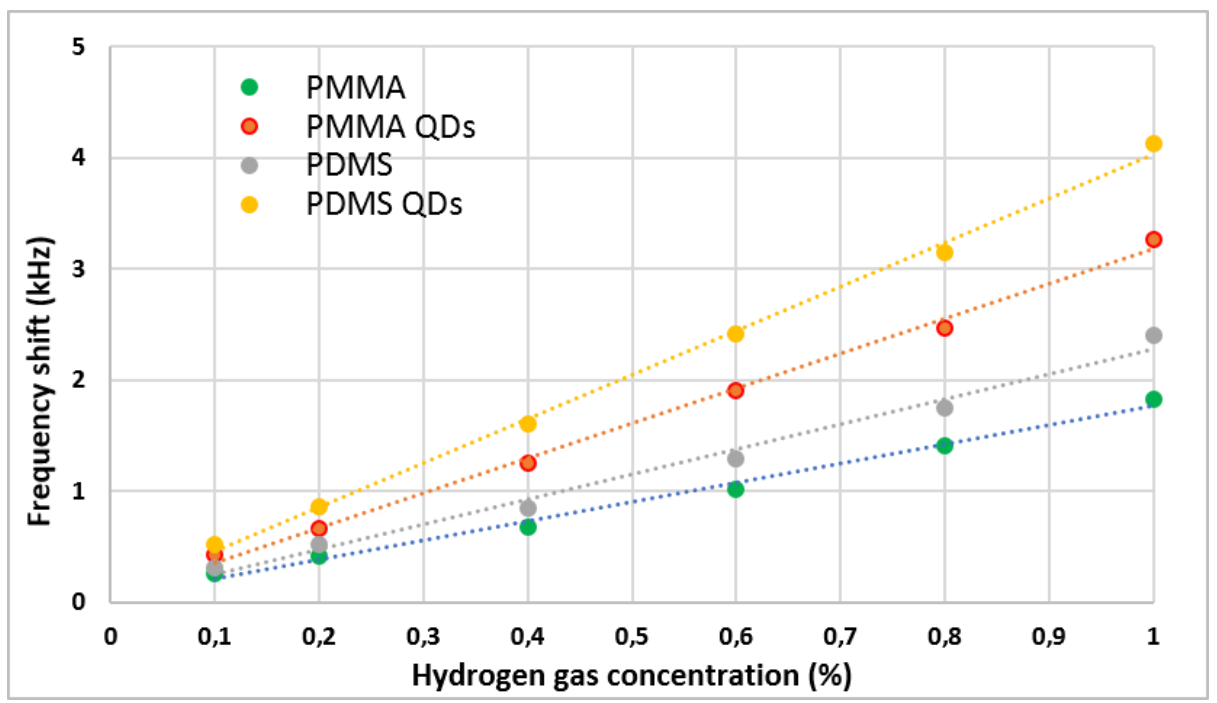

Figure 4. Frequency shift of the sensors for different concentrations of hydrogen.

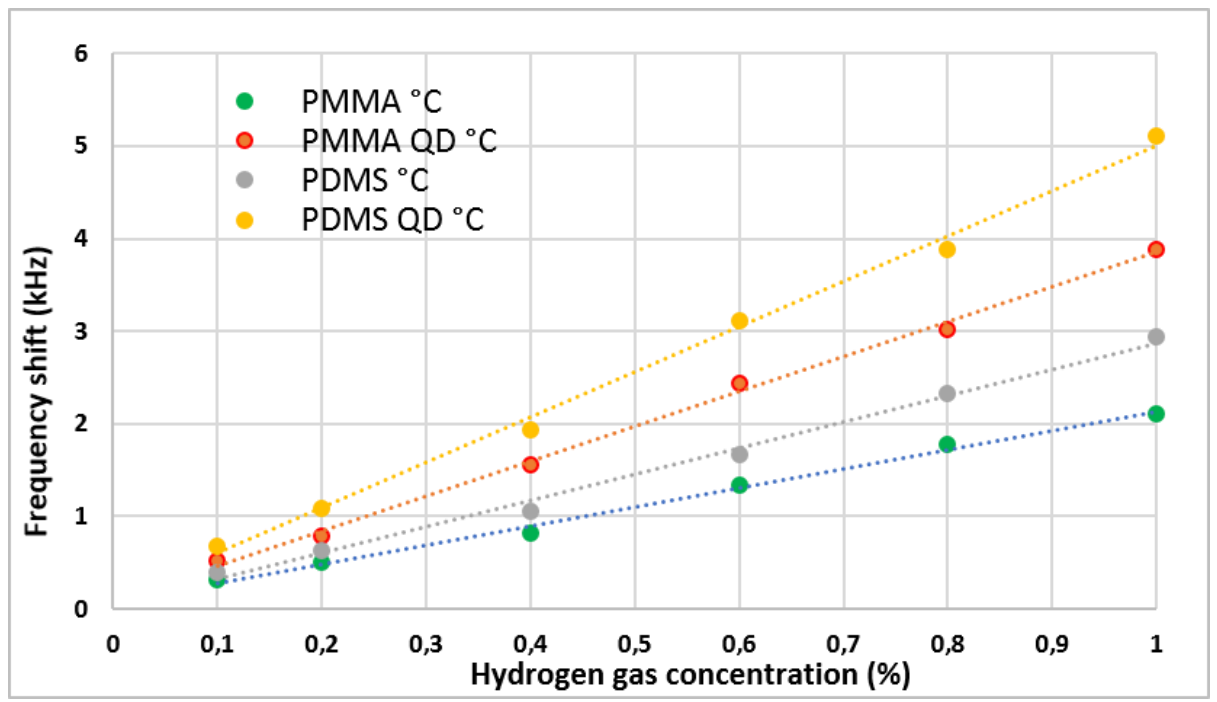

Figure 5. Frequency shift of the sensors after heat treatment for different concentrations of hydrogen.

In order to further analyze the degree of influence of the presence of QDs and of the heat treatment, Figure 6 presents the results of the frequency shifts for the sensors with PDMS at a hydrogen concentration of $8 \%$. As can be seen, the heat treatment on the polymeric film of PDMS led to an increase in frequency shift of $0.58 \mathrm{kHz}$ (about 20\%). The addition of QDs in the PDMS film, however, led to an increase of $1.4 \mathrm{kHz}$, which is about two times higher than the increase observed when only the 
heat treatment was applied on the film (40\%). When both methods of sensitivity enhancement were applied, the frequency shift increased by about $2 \mathrm{kHz}$, which means an increase of about three times greater (55\%) than the increase observed when improving only with heat treatment. As a conclusion, QDs have the greatest contribution to the improvement of the sensitivity of the sensors and the heat treatment is an important parameter that helps to improve the sensors' performance.

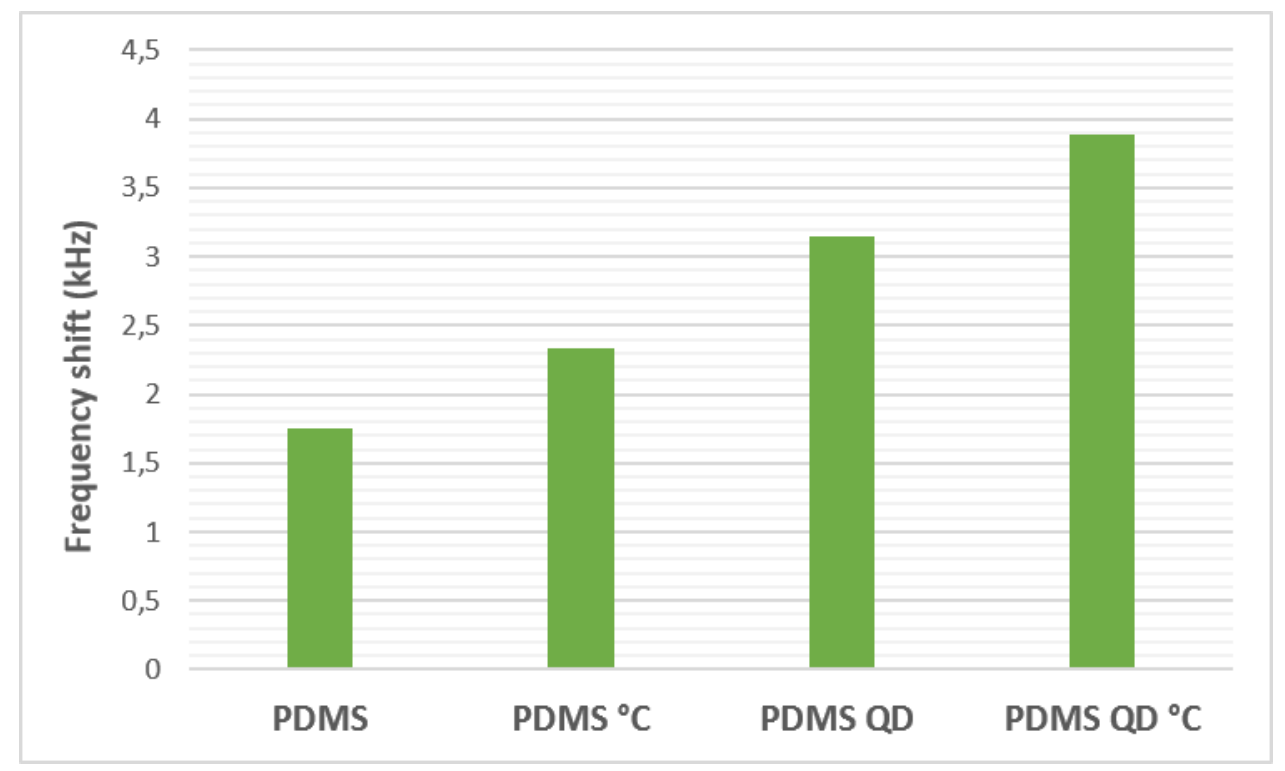

Figure 6. The frequency shifts for the sensor with polydimethylsiloxane (PDMS) at an $8 \%$ concentration of hydrogen.

Figure 7 shows the dynamic response of the PMMA QDs sensor at different analyte concentrations. As can be seen, the sensor is reversible both at lower concentrations and at higher concentrations. When polymers are used in this application, the reversibility property is very important because they can react through the functional groups with the gases to be tested. Repeating 10 measurements of the frequency deviation for each sensor, at the same concentration, yielded errors below $\pm 3.7 \%$.

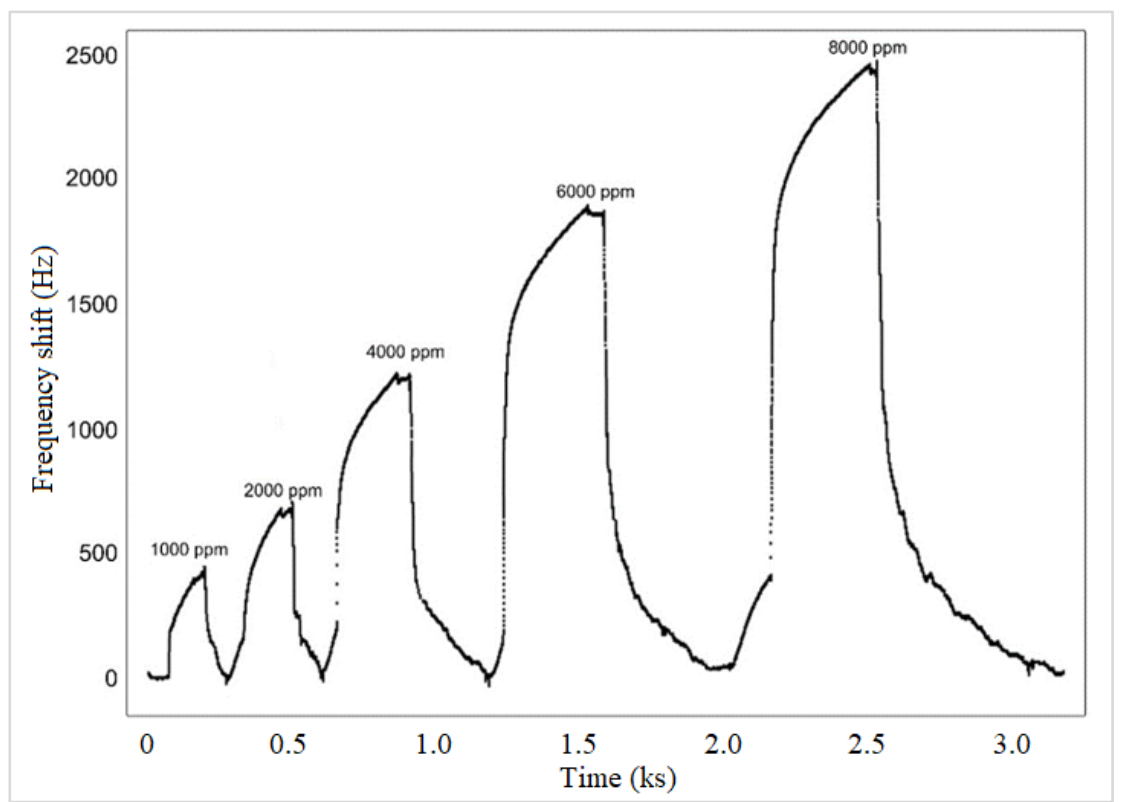

Figure 7. Dynamic response of sensor PMMA QDs to hydrogen for various concentrations. 
The results obtained with PDMS QDs ${ }^{\circ} \mathrm{C}$ sensor are comparable with results from literature, such as those presented in Table 3. As far as can be seen, there are still challenges in obtaining sensors that operate at room temperature and which offer the highest sensitivity, with lover LOD. QDs also present a very good perspective for developing SAW sensor for other types of gases, both by varying the type of sensitive material and by using it within a composite material.

Table 3. Comparison of the results obtained in the literature for other SAW hydrogen sensors.

\begin{tabular}{ccccc}
\hline Sensitive Materials & Sensitivity & Limit of Detection & Working Temperature & Reference \\
\hline $\mathrm{Pd} / \mathrm{WO}_{3}$ & $0,13 \mathrm{~Hz} / \mathrm{ppm}$ & $4540 \mathrm{ppm}$ & Room temperature & {$[5]$} \\
$\mathrm{CuPc} / \mathrm{Pd}$ & $1 \mathrm{kHz}$ to $5000 \mathrm{ppm}$ & & $370{ }^{\circ} \mathrm{C}$ & {$[30]$} \\
$\mathrm{ZnO}$ nanowires & $0.015 \mathrm{~Hz} / \mathrm{ppm}$ & $2117 \mathrm{ppm}$ & Room temperature & {$[31]$} \\
$\mathrm{Pd}$ modified $\mathrm{SnO}_{2}$ & $1159 \mathrm{kHz}$ to $2000 \mathrm{ppm}$ & - & $175^{\circ} \mathrm{C}$ & {$[32]$} \\
$\mathrm{ZnO}$ nanowires & 0,62 & $2253 \mathrm{ppm}$ & Room temperature & {$[33]$} \\
$\mathrm{PDMS}$ with $\mathrm{Si} / \mathrm{SiO}_{2}$ QDs & 0,54 & $452 \mathrm{ppm}$ & Room temperature & The present work \\
\hline
\end{tabular}

\section{Conclusions}

In this work, SAW sensors with thin polymeric and composite films were developed and studied for hydrogen detection at room temperature. The polymer films were made by PMMA and PDMS, and the composite films were made from Si QDs incorporated into the specified polymers. Also, the effect of a heat treatment at $80^{\circ} \mathrm{C}$ on the frequency shift of the sensor was studied. The best results were recorded by the sensors with quantum dots, because of the large specific area that favored the mass accumulation. Also, better results were obtained after the heat treatment made on thin films. The best result was obtained by the sensor with PDMS and QDs after heat treatment. Thus, the PDMS QDs ${ }^{\circ} \mathrm{C}$ sensor had a LOD $452 \mathrm{ppm}$, at room temperature. These results challenge us towards a more detailed study of the use of QDs in thin films for SAW sensors and for optimizing the temperature, which will lead to much better results.

Author Contributions: Conceptualization, C.V. and I.C.; Formal analysis, C.V.; Writing-original draft, I.C.; Writing-review \& editing, C.V. and I.C.

Funding: This work was supported by a grant of the Romanian Ministry of Research and Innovation, CCCDI-UEFISCDI, project number PN-III-P1-1.2-PCCDI-2017-0172/15PCCDI and project NUCLEU 16N/08.02.2019.

Acknowledgments: The authors want to thank Ruxandra Birjega for the X-ray diffraction.

Conflicts of Interest: The authors declare no conflict of interest.

\section{References}

1. Mujahid, A.; Dickert, F.L. Surface Acoustic Wave (SAW) for Chemical Sensing Applications of Recognition Layers. Sensors 2017, 17, 2716. [CrossRef] [PubMed]

2. Ballantine, D.S.; White, R.M.; Martin, S.J.; Ricco, A.J.; Zellers, E.T.; Frye, G.C.; Wohtjen, H. Acoustic Wave Sensors, Theory, Design, and Physico-Chemical Applications; Academic Press: Cambridge, MA, USA, 1997.

3. Choodum, A.; Keson, J.; Kanatharana, P.; Limsakul, W.; Wongniramaikul, W. Selective pre and post blast trinitrotoluene detection with a novel ethylenediamine entrapped thin polymer film and digital image colorimetry. Sens. Actuators B Chem. 2017, 252, 463-469. [CrossRef]

4. Jasek, K.; Pasternak, M.; Grabka, M.; Neffe, S.; Zasada, D. Deposition of Polymer Sensor Films on SAW Surface by Electrospraying Technology. Arch. Acoust. 2017, 42, 507-513. [CrossRef]

5. Miu, D.; Birjega, R.; Viespe, C. Surface Acoustic Wave Hydrogen Sensors Based on Nanostructured $\mathrm{Pd} / \mathrm{WO}_{3}$ Bilayers. Sensors 2018, 18, 3636. [CrossRef] [PubMed]

6. Esmeryan, K.D. Application of Thin Metal Oxide Films in Acoustic Wave Chemical Sensors. Biosens. Bioelectron. 2015, 6, 163. [CrossRef]

7. Constantinoiu, I.; Viespe, C. Detection of Volatile Organic Compounds Using Surface Acoustic Wave Sensor Based on Nanoparticles Incorporated in Polymer. Coatings 2019, 9, 373. [CrossRef] 
8. Sayago, I.; Fernández, M.; Fontecha, J.; Horrillo, M.; Vera, C.; Obieta, I.; Bustero, I. New sensitive layers for surface acoustic wave gas sensors based on polymer and carbon nanotube composites. Sens. Actuators $B$ Chem. 2012, 175, 67-72. [CrossRef]

9. Kim, W.; Jang, B.; Lee, H.-S.; Lee, W. Reliability and selectivity of H2 sensors composed of Pd Film nanogaps on an elastomeric substrate. Sens. Actuators B Chem. 2016, 224, 547-551. [CrossRef]

10. Gonçalves, H.; Jorge, P.A.; Fernandes, J.; Da Silva, J.C.E.; Fernandes, J.R.A.; Da Silva, J.E. Hg(II) sensing based on functionalized carbon dots obtained by direct laser ablation. Sens. Actuators B Chem. 2010, 145, 702-707. [CrossRef]

11. Li, M.; Kan, H.; Chen, S.; Feng, X.; Li, H.; Li, C.; Fu, C.; Quan, A.; Sun, H.; Luo, J.; et al. Colloidal quantum dot-based surface acoustic wave sensors for $\mathrm{NO}_{2}$-sensing behavior. Sens. Actuators B Chem. 2019, 287, 241-249. [CrossRef]

12. Li, H.; Li, M.; Kan, H.; Li, C.; Quan, A.; Fu, C.; Luo, J.; Liu, X.; Wang, W.; Yang, Z.; et al. Surface acoustic wave $\mathrm{NO}_{2}$ sensors utilizing colloidal SnS quantum dot thin films. Surf. Coat. Technol. 2019, 362, 78-83. [CrossRef]

13. De Vero, J.; Jasmin, A.; Dasallas, L.; Garcia, W.; Sarmago, R. Synthesis of Iron Oxide Nanostructures via Carbothermal Reaction of Fe Microspheres Generated by Infrared Pulsed Laser Ablation. Coatings 2019, 9, 179. [CrossRef]

14. Kim, M.; Osone, S.; Kim, T.; Higashi, H.; Seto, T. Synthesis of Nanoparticles by Laser Ablation: A Review. KONA Powder Part. J. 2017, 34, 80-90. [CrossRef]

15. Wang, W.; Liu, X.; Mei, S.; Jia, Y.; Liu, M.; Xue, X.; Yang, D. Development of a Pd/Cu nanowires coated SAW hydrogen gas sensor with fast response and recovery. Sens. Actuators B Chem. 2019, 287, 157-164. [CrossRef]

16. Li, Z.; Yao, Z.; Haidry, A.A.; Plecenik, T.; Xie, L.; Sun, L.; Fatima, Q. Resistive-type hydrogen gas sensor based on TiO2: A review. Int. J. Hydrogen Energy 2018, 43, 21114-21132. [CrossRef]

17. Nugroho, F.A.A.; Darmadi, I.; Cusinato, L.; Susarrey-Arce, A.; Schreuders, H.; Bannenberg, L.J.; Fanta, A.B.D.S.; Kadkhodazadeh, S.; Wagner, J.B.; Antosiewicz, T.J.; et al. Metal-polymer hybrid nanomaterials for plasmonic ultrafast hydrogen detection. Nat. Mater. 2019, 18, 489-495. [CrossRef]

18. Willis, A.G.; Haron, S. Synthesis of composite thin-film polymer consisting of tungsten and zinc oxide as hydrogen gas detector. In Proceedings of the 7th Conference on Emerging Energy and Process Technology, Johor Bahru, Malaysia, 27-28 November 2018.

19. Iftikhar, M.A.; Awattif, A.M. CdS/PMMA-based inorganic/organic heterojunction for $\mathrm{H}_{2} \mathrm{~S}$ gas sensing. Chalcogenide Lett. 2017, 14, 133-138.

20. Al-Mashat, L.; Tran, H.D.; Wlodarski, W.; Kaner, R.B.; Kalantar-Zadeh, K. Polypyrrole nanofiber surface acoustic wave gas sensors. Sens. Actuators B Chem. 2008, 134, 826-831. [CrossRef]

21. Viespe, C.; Miu, D. Characteristics of Surface Acoustic Wave Sensors with Nanoparticles Embedded in Polymer Sensitive Layers for VOC Detection. Sensors 2018, 18, 2401. [CrossRef]

22. Baik, K.H.; Jung, S.; Ren, F.; Pearton, S.J.; Jang, S. Moisture Insensitive PMMA Coated Pt-AlGaN/GaN Diode Hydrogen Sensor and Its Thermal Stability. ECS J. Solid State Sci. Technol. 2018, 7, Q3009-Q3013. [CrossRef]

23. Hou, L.; Xu, B.; Kang, J.; Zhao, C.; Jin, S. Sensitivity-enhanced Fabry-Perot filled with PDMS temperature sensor based on Vernier effect. In Proceedings of the Asia Communications and Photonics Conference (ACP), Hangzhou, China, 26-29 October 2018. [CrossRef]

24. Li, Y.; Shen, W.; Zhao, C.; Xu, B.; Wang, D.; Yang, M. Optical hydrogen sensor based on PDMS-formed double-C type cavities with embedded Pt-loaded $\mathrm{WO}_{3} / \mathrm{SiO}_{2}$. Sens. Actuators B Chem. 2018, 276, $23-30$. [CrossRef]

25. Campbell, C. Surface Acoustic Wave Devices and Their Signal Processing Applications; Academic Press: Cambridge, MA, USA, 1989.

26. Sima, C.; Viespe, C.; Nicolae, I.; Grigoriu, C.; Prodan, G.; Ciupina, V.; Cismileanu, A.; Nistor, C.L.; Nicolae, C.-A.; Donescu, D. Functionalized Si/SiO2 quantum dots. SPIE Proc. 2007, 6785, 67850K.

27. Benetti, M.; Cannatà, D.; Verona, E.; Palla Papavlu, A.; Dinca, V.; Lippert, T.; Dinescu, M.; Di Pietrantonio, F. Highly selective surface acoustic wave e-nose implemented by laser direct writing. Sens. Actuators B Chem. 2019, 283, 154-162. [CrossRef]

28. Ghannam, M.T.; Esmail, M.N. Rheological Properties of Poly(dimethylsiloxane). Ind. Eng. Chem. Res. 1998, 37, 1335-1340. [CrossRef]

29. Pawar, E. A Review Article on Acrylic PMMA. IOSR JMCE 2016, 13, 1-4. [CrossRef] 
30. Jakubika, W.; Urbańczyk, M.; Maciak, E.; Krzywiecki, M. Bi-layer nanostructures of CuPc and Pd in SAW and resistance hydrogen sensor. Sens. Actuator B Chem. 2012, 175, 255-262. [CrossRef]

31. Marcu, A.; Viespe, C. Surface Acoustic Wave Sensors for Hydrogen and Deuterium Detection. Sensors 2017, 17, 1417. [CrossRef]

32. Yang, L.; Yin, C.; Zhang, Z.; Zhou, J.; Xu, H. The investigation of hydrogen gas sensing properties of SAW gas sensor based on palladium surface modified $\mathrm{SnO}_{2}$ thin film. Mater. Sci. Semicond. Process. 2017, 60, 16-28. [CrossRef]

33. Marcu, A.; Viespe, C. Laser-grown $\mathrm{ZnO}$ nanowires for room-temperature SAW-sensor applications. Sens. Actuators B Chem. 2015, 208, 1-6. [CrossRef]

(C) 2019 by the authors. Licensee MDPI, Basel, Switzerland. This article is an open access article distributed under the terms and conditions of the Creative Commons Attribution (CC BY) license (http://creativecommons.org/licenses/by/4.0/). 